\title{
A Health Education Perspective on Sexual Risk Taking Behavior in Perimenopausal Women
}

\author{
Silvea Thomas \\ Kingsborough Community College
}

\begin{abstract}
Perimenopausal women between the ages of 45-55 years, experiencing the physical, emotional, social and mental metamorphosis, are often overlooked when sexually transmitted disease issues are addressed. They are often not viewed as risk takers. Yet millions are as vulnerable as the young for sexually transmitted diseases. These women are being described as risk takers for a variety of reasons including a lack of knowledge, low condom use, society's unawareness, myths regarding their asexuality, the noninclusion approach of the media to sexually transmitted diseases risk for this group and the lack of readily available data to support societal attention and action. The need for inclusive health education strategies is suggested. Health educators need to be proactive and at the same time prepare perimenopausal women to become their own advocates.
\end{abstract}

(C) 2004 Californian Journal of Health Promotion. All rights reserved.

Keywords: perimenopausal women, health education strategies, sexually transmitted diseases

\section{Introduction}

Each year, millions of women become infected with one or more forms of sexually transmitted diseases (STD's) with nearly one half contracting a life long infection. Among those infected are a seemingly invisible population of perimenopausal women for whom health promotion and disease prevention has not always been a priority for the health professionals.

Accurate statistics on incidents and prevalence for this group (45-55 yrs.) is difficult to obtain as identified data is only an estimate. In a pertinent study estimating the "incidents and prevalence of STD's in the United States”, some of the difficulties in obtaining statistical data were identified. These difficulties included errors of underestimation of the magnitude of the infections, under reporting of the extent of the infections, inaccuracies in reported data, not all sexually transmitted diseases require notification and the effect of the surveillance priorities of some States (Cates, 1999). These difficulties have impacted negatively on the perimenopausal woman.
If we exclude human immune virus (HIV), sexually transmitted diseases add billions of dollars to our health care cost each year, yet like most other lifestyle diseases, these are preventable (SIECUS, 2002; Cates, 1999). Because a number of these sexually transmitted diseases are asymptomatic, many times treatment is not sought even though quality of life is impacted. Asymptomatic diseases can include, chlamydia, gonorrhea, syphilis, genital herpes, hepatitis $\mathrm{B}$, trichomoniasis , bacterial vaginosis and human papilloma virus (HPV). There are for example, approximately thirty distinct types of HPV that can affect the genitals. Some cause genital warts while others do not, some are easily diagnosed while others are not. These factors place women at risk for cervical cancer regardless of age. In the case of herpes simplex type II, more than one in five American adults are diagnosed with the disease long after being infected, prompting some researchers to call this disease the "no not me" phenomenon (CDC, 2000; Steen et al., 1999). 


\section{Literature Review}

Research of the present literature indicate a lack of interest in research about the sexual behavior of women who have passed the childbearing age. Women in this age group are underrepresented in all statistics where sexually transmitted diseases are concerned. This lack of interest has been described as "regrettable" because there are many older Americans with more than one risk factor for sexually transmitted diseases, including HIV, who continue to engage in risky sexual practices (Butler, 1994). Usually it is the risks associated with the sexual practices of the young that is given the attention. Could it be that society does not see perimenopausal women as risk takers and therefore not vulnerable? Or that society and the health professions in particular associate risk-taking behaviors with youthfulness? Not to be dismissed is the continuing risk taking behaviors that are partly due to the belief that after child bearing and menopause, women become disengaged from sexual thoughts, feelings and behaviors.

The inaccuracies and lack of available data presently indicates that for women age forty four and older, the numbers with STD's in this country is declining. These statistics only goes to support the belief that there is presently a minimal amount of research in this area. If health professionals really believe that sexually transmitted diseases are increasing in the population, then the impact is not reflected in the available published data for those aged fortyfive and older.

The latest Centers for Disease Control (CDC) data on STD among women show the following estimates in the numbers diagnosed or infected: those aged 40-44 years was 45.6 per 100,000 , those aged 45-54 years, was 16.9 per 100,000 and those aged 55-64 years was 5.4 per 100,000. (CDC, 2003). The decline in the number of people diagnosed as they get older, may indicate less use of the health services or less access, or a lack of focus on the needs of women who are not of childbearing age.

In some instances, risk taking behaviors results from a lack of knowledge of the consequences of the normal physical changes associated with menopause. These changes include thinning of the vaginal walls, diminished lubrication increasing the risk of injury to vaginal tissue and hence an increased risk of contracting a sexually transmitted disease. Other sources of vulnerability include the reduced competence of the immune system and the masking of symptoms by multi-systems disease not often associated with the perimenopausal period.

According to one researcher, sexually transmitted diseases are difficult to track as many people are asymptomatic and therefore remain undiagnosed (Grigg, 2000). Presently there are no national surveillance data on trichimoniasis, bacterial vaginosis and related vaginal infections, yet these infections are among the most common conditions found in perimenopausal women. Untreated bacterial vaginosis (BV) is associated with pelvic inflammatory disease and both trichomoniasis and bacterial vaginosis may increase the risk of HIV infection. Chancroid also caused by a bacterial infection produce genital ulcers. While not thought to be widespread, it is said to be "substantially under diagnosed and under reported.” Difficulty in diagnosis is associated with healthcare facilities not having the capacity to perform the necessary diagnostic tests.

Research indicates that not all physicians ask perimenopausal women about sexual activity outside of a monogamous relationship or whether any form of contraceptive protection is used (Skiest \& Keiser, 1997). Another study from the U.S. Office of Women's Health reported on a nationwide questionnaire survey that asked physicians to indicate whether women who were not adolescents were asked about their sexual practices including, condom use, number of sexual partners and sexually transmitted diseases at their interview. The majority of the physicians who completed the questionnaire indicated that they were more likely to ask about sexual activity if the patient was an adolescent than if the patient was older. Factors found to foster their omission included a lack of time for consultation and subscribing to the myth of postchildbearing asexuality (CDC, 1997). This lack of questioning by physicians, miss an immense 
opportunity for education and greatly increase vulnerability for sexually transmitted diseases in perimenopausal women.

Perimenopausal women themselves may not associate the inability to become pregnant with the risk of acquiring a sexually transmitted disease, so that their poor treatment seeking behaviors, the stigma of clinic attendance, and the negative attitudes of healthcare providers compound an already under recognized situation. Researchers suggest traditional gender roles as yet another reason why some women might not talk about sex, condom use, or ask a partner to use a condom. Low condom use during vaginal and anal intercourse is known to be a potential means of continuing the spread of infectious diseases (Stahl \& Catania, 1994). Non-assertion in this type of situation could be related to an inability to talk about sexual issues related to fears of rejection or abuse (McEnvoy, 2001). Indications are that the numbers of healthy perimenopausal women who remain sexually active are increasing. The need is therefore urgent to ensure this age group is well informed.

A national survey on aging found many people aged 55 years and older reported that they were looking forward to being healthy in old age (National Survey on Aging Research, 2001). They saw this time of their life as providing the opportunity to spend more time with their family and friends, pursue hobbies and have more leisure time. In spite of this positive outlook, there are those who still worry about contracting a disease. Their desire is to be healthy, and to have a life of quality rather than quantity. Among those surveyed, seventy four percent suggested that more money should be spent on studying how to prevent diseases rather than on how to cure diseases (Perry, 2001).

\section{Strategies for Prevention}

Health education can assist perimenopausal women in developing a knowledge base about sexually transmitted diseases that will assist them in their health decisions. The focus should therefore include the identification of risk factors, through a detailed sexual history aimed at determining levels of risk, and descriptions of the transmission sexually transmitted diseases including the exclusive nature of their heightened risk.

One of the key factors related to the transmission of sexually transmitted diseases is a low prevalence of condom use. Perimenopausal women need to be taught how to use a condom as a major method of protection. Approximately 24 billion condoms should be used yearly but presently only six to nine million are reported as being used in Population Report (1998).

Because of the sensitive nature of the information and the risky nature of the behavior, support should be available to encourage perimenopausal women to attend screening sessions, even when in a monogamous relationship. One suggestion is to have "a couple-testing night" where the focus would be on screening both partners, as a means of normalizing testing and making it a part of a routine physical examination (Stewart, 2000).

Another approach could be a "Risk Assessment" checklist for sexually transmitted diseases. This can be quickly and easily done and included as part of the personal health records. This would assist in focusing the attention of the health care provider when there are "time constraints." The knowledge about perimenopausal changes and its implication for a healthier lifestyle can then be viewed as relevant. Worksite health promotion and disease prevention strategies should include liaisons with other organizations that also promote women's health as presently large parts of the workforce are women.

Because of the desire to be healthy and to have quality rather quantity of life, perimenopausal women should be assisted to advocate for the services they need to promote their own health status and to prevent diseases. Researchers recognize the need for federal funding for research about women and menopausal issues and should be supported in any effort to obtain funding.

The use of media messages and visual aids on condom use is essential for the education of women of all ages. These messages should be 
designed and presented in such a way that the perimenopausal women can also identify with them. We are reminded that media messages should be about health and not about ageism, hence the need to broaden its focus making the messages relevant to the perimenopausal woman. The provision of printed information should always be readily available and accessible to this age group.

\section{Conclusion}

This invisible population of perimenopausal women with less knowledge, less awareness and less urgency about protecting themselves, with fears about the consequences of taking control of their sexuality, is at great risk. Guidance and encouragement is needed to support their need for seeking out information.

Additionally, there is the need to identify the reasons for their vulnerability, so as to further determine what are the responsibilities of the perimenopausal woman as well as that of the health professionals who provide the care.

If perimenopausal women are expecting to live to a healthy old age, then the approach to health education should be such that individuals are empowered to recognize and present their aspirations as a valid activity. This empowerment will allow for the creation of options, the exercise of choice, the adoption of healthy lifestyles, and the development of skills that will result in change. Developing preventive strategies to meet these desires is not beyond the scope of the health educators. Every effort should therefore be made to plan innovative strategies that will assist perimenopausal women in reducing risk taking behaviors and develop healthier lifestyles.

\section{References}

Butler, R. N. (1993, March). AIDS: Older Americans aren’t immune. Geriatrics, 48, 9-10.

Belden Russonello \& Stewart (2000). Great expectations: Americans' Views on aging. Results from a national survey on aging research. The Alliance for Aging Research. Retrieved January 15, 2003 from http://www.agingresearch.org/survey/pollsummary.1cfm

Cates, W. Jr. (1999). Estimates of the incidence and prevalence of sexually transmitted diseases in the United States. Sexually transmitted disease, 26 (Suppl.), S2-S7.

Centers for Disease Control and Prevention. (2000). Tracking the hidden epidemics: Trends in STDs in the United States. Retrieved January 15, 2003.from http://www.cdc.gov/nchstp/dstd/stasTrends/Trends2000.htm

Centers for Disease Control and Prevention. (1997). An overview for women. Atlanta, GA: CDC Office of Women's Health, pp. 1-4.

Centers for Disease Control and Prevention. (1998). Guidelines for the treatment of sexually transmitted diseases. Morbidity and Mortality Weekly Report, 47(RR-1), 1-111.

Centers for Disease Control and Prevention. (1994). HIV prevention practices of primary care physicians - United States, 1992. Morbidity and Mortality Weekly Report, 42(51), 988-992.

Grigg, E. (2000). STD and older people. Nursing Standard 14(39), 48-53.

SIECUS. (2001). Fact sheet: Sexually transmitted disease in the Unites States. Association of Reproductive Health Professionals, 30, 1-2.

Skiest, D. J., \& Keiser, P. (1997). Human immuno-deficiency virus infection in patients older than 50 years: A survey of primary care physicians’ beliefs, practices and knowledge. Archives of Family Medicine, 6, 89-94.

Stahl, R., \& Catania, J. (1994). AIDS risk behaviors among late middle-aged and elderly Americans. National AIDS behavioral survey. Archives of Internal Medicine, 154, 57-63.

Steen, R., \& Dallabetta, G. (1999). The use of epidemiologic mass treatment \& syndrome management for sexually transmitted disease control. Sexually Transmitted Disease, 28 (Suppl.), S12-S20.

Stewart, F. H. (2000). New strategies for std prevention and control, "STD forum: Conspiracy to innovate.” Association of Reproductive Health Professionals, 29, 1-2. 
Author Information

Silvea Thomas, EdD, RN, CHES, Professor

Kingborough Community College

Brooklyn, NY

E-Mail: silveat@aol.com 